\title{
Effects of electrical stimulation on cell activity, cell cycle, cell apoptosis and $\beta$-catenin pathway in the injured dorsal root ganglion cell
}

\author{
MING HU, LI HONG, SONGMING HE, GUOTAO HUANG, YANXIANG CHENG and QIAN CHEN
}

Department of Gynecology and Obstetrics, Renmin Hospital of Wuhan University, Wuhan, Hubei 430060, P.R. China

Received January 28, 2019; Accepted March 11, 2020

DOI: $10.3892 / \mathrm{mmr} .2020 .11058$

\begin{abstract}
The present study aimed to investigate the effects of electrical stimulation (ES) on cell activity, cell cycle and apoptosis in injured rat dorsal root ganglion (DRG) cells induced by cyclic mechanical stretching (CMS). The present study also investigated whether the Wnt/ $\beta$-catenin pathway is involved in this process. Injury and ES models were established in DRG cells. Then, cell activity was detected using a Cell Counting Kit-8 and 5-ethynyl-2'-deoxyuridine-594 cell proliferation assay kit. Cell cycle distribution was detected using a cell cycle detection kit. Apoptosis was detected using an Annexin V-FITC apoptosis detection kit, and $\mathrm{Wnt} / \beta$-catenin pathway-associated proteins were detected using western blotting. The present study demonstrated that CMS decreased DRG cell activity, increased the number of cells in the $S$ phase, promoted cell apoptosis and inhibited the Wnt/ $\beta$-catenin pathway. In addition, ES significantly increased the proliferation activity of DRG cells, increased the number of cells in the G2 phase, decreased the apoptotic rate and activated the $\mathrm{Wnt} / \beta$-catenin pathway, ultimately reversing the injury caused by CMS. Following inhibition of the Wnt/ $\beta$-catenin signaling pathway using XAV939, the effects of ES were weakened. In conclusion, the present study demonstrated that ES may reverse CMS-induced injury in DRG cells, and that the Wnt signaling pathway may be involved in this process.
\end{abstract}

\section{Introduction}

Stress urinary incontinence (SUI), a type of female pelvic floor dysfunction, is a clinically common disease in gynecology with an increasing incidence rate of $38-49.2 \%$ globally (1). This condition refers to the spontaneous spilling of urine

Correspondence to: Professor Li Hong, Department of Gynecology and Obstetrics, Renmin Hospital of Wuhan University, 238 Jiefang Road, Wuhan, Hubei 430060, P.R. China

E-mail: lihong_whu@163.com

Key words: electrical stimulation, dorsal root ganglion cells, peripheral nerve injury, Wnt/ $\beta$-catenin pathway when abdominal pressure increases during bladder detrusor relaxation (2). SUI occurs primarily in postpartum and postmenopausal women, and can seriously affects women's quality of life, and physical and mental health (3). It also causes a large social and economic burden (4,5). A type of physiotherapy known as pelvic electrical stimulation (PES) has demonstrated good clinical effects in patients with mild-to-moderate symptoms (6-8). However, the specific molecular mechanism underlying this treatment remains unclear.

Studies have demonstrated that pudendal nerve (PN) damage induces SUI by causing denervation of the pelvic floor muscles (9-11). At the same time, electrical stimulation (ES) has been demonstrated to promote the repair of the central and peripheral nervous system following injury (12-14). These studies indicated that the therapeutic effect of PES in SUI may be achieved by promoting the repair of damaged PNs.

The Wnt/ $\beta$-catenin signaling pathway is associated with development of the nervous system, stem cell proliferation and differentiation, and axon guidance (15). Studies of neurodegenerative diseases have demonstrated that the $\mathrm{Wnt} / \beta$-catenin signaling pathway regulates the proliferation and differentiation of neural stem cells and their precursor cells in the spinal cord $(16,17)$. In addition, animal models of spinal cord injury have indicated that ES influences the proliferation and directional migration of nerve cells via the Wnt/ $\beta$-catenin signaling pathway (18-20). In the field of oncology, it has been demonstrated that inhibition of the Wnt signaling pathway can lead to inhibition of cell proliferation and cell cycle, as well as the expression levels of $\beta$-catenin, which are associated with the activation and shutdown of Wnt signaling that regulates expression levels of downstream target genes, such as cyclin D1, C-myc, E-cadherin and Lgr5, at the transcriptional level, thereby influencing the progression of tumors (21-25).

The present study simulated nerve injury by constructing a cyclic mechanical stretching (CMS) injury model in rat dorsal root ganglion (DRG) cells. Cells were subjected to fixed-parameter ES, and changes in the cell cycle and levels of cell activity, apoptosis and Wnt/ $\beta$-catenin signaling pathway-related proteins were detected. Finally, the inhibitor XAV939 was used to inhibit the Wnt/ $\beta$-catenin signaling pathway and changes in DRG cell proliferation activity were detected. The present study aimed to provide a basis for further studies to clarify the specific mechanisms of ES in the treatment of SUI and discover new potential targets. 


\section{Materials and methods}

Cell resource and groups. DRG cell line was purchased from Zhen Shanghai and Shanghai Industrial Co., Ltd. (cat. no. HZ-C644) and maintained in DMEM (Jenom Biomedical Technology Co., Ltd.) containing $15 \%$ fetal bovine serum (FBS; Gibco; Thermo Fisher Scientific, Inc.), $100 \mathrm{U} / \mathrm{ml}$ penicillin $\mathrm{G}$ and $100 \mu \mathrm{g} / \mathrm{ml}$ streptomycin. DRG cells were divided into four groups: Control (DRG cells received no treatment), ES (DRG cells treated with ES only), injury (CMS; DRG cells treated with CMS only) and treatment group (CMS + ES; DRG cells treated with CMS, followed by treatment with ES immediately).

Establishment of DRG cell injury model. DRG cells were cultured on culture plates precoated with rat tail collagen (Sigma-Aldrich; Merck KGaA). When cell density reached $80-90 \%$, the culture plates were transferred onto mechanical loading culture dishes. CMS was performed using a four-point bending device (Chengdu Power Technology Co., Ltd), which stresses cells by bending the cell plate up and down. The instrument mainframe was used to adjust the CMS parameters and the control power system was used to perform the mechanical stretching. A previous study determined the appropriate parameters to be $5,333 \mu$ strain $(4 \mathrm{~mm}), 8 \mathrm{~h}$ and $1 \mathrm{~Hz}$, which were used in the present experiment (26). All cells received treatments under the identical environmental conditions. The principle of cell mechanics loading is presented in Fig. 1.

ES model. The ES device was constructed with reference to the method described by Song et al (27) and our device was proven to be stable after continuous improvement. The unit included a direct current power supply, a conducting device and a trending circular petri dish (Fig. 2). The electric field strength was set using a DC power source (model no. 3303A; Topward Electric Instruments Co., Ltd.). The culture plates were placed in a circular culture dish (diameter, $18 \mathrm{~cm}$ ) filled with DMEM containing 15\% FBS, $100 \mathrm{U} / \mathrm{ml}$ penicillin G and $100 \mu \mathrm{g} / \mathrm{ml}$ streptomycin, and fixed by internal small baffle. A total of three cell culture plates could be placed together in a circular culture dish for ES. The electric circuit was formed of a DC power source, positive and negative electrodes, a wire, an $\mathrm{Ag} / \mathrm{AgCl}$ electrode, a saturated $\mathrm{KCl}$ electrolyte, an agarose bridge and a culture dish (filled with DMEM, supplemented with $15 \%$ FBS, $100 \mathrm{U} / \mathrm{ml}$ penicillin G and $100 \mu \mathrm{g} / \mathrm{ml}$ streptomycin). The ES parameters were set to $100 \mathrm{mV} / \mathrm{mm}$ and $1 \mathrm{~h}$, in accordance with a previous study (28).

Cell proliferation analysis. A Cell Counting Kit-8 (CCK-8; cat. no. C0037; Beyotime Institute of Biotechnology) was used to detect cell viability, according to the manufacturer's protocol. Following treatment with CMS or ES, DRG cells were collected and adjusted to 2,000,000 cells/ml using a cell counting instrument. The cell suspension $(100 \mu \mathrm{l} /$ well $)$ was pipetted into a 96 -well plate and incubated in $5 \% \mathrm{CO}_{2}$ at $37^{\circ} \mathrm{C}$ for $2 \mathrm{~h}$. CCK-8 solution ( $10 \mu \mathrm{l} /$ well) was added to each well and incubated in $5 \% \mathrm{CO}_{2}$ at $37^{\circ} \mathrm{C}$ for $1 \mathrm{~h}$. Finally, the optical density (OD) was measured at $450 \mathrm{~nm}$ using a microplate reader (Victor 3; PerkinElmer, Inc.).
A 5-ethynyl-2'-deoxyuridine (EdU)-594 cell proliferation assay kit (cat. no. C0078; Beyotime Institute of Biotechnology) was used to detect cell proliferation activity. Following the treatment of each group, pre-warmed $10 \mu \mathrm{mol} / 1 \mathrm{EdU}$ solution ( $2 \mathrm{ml} / \mathrm{plate})$ was added to each of the plates, which were incubated for $2 \mathrm{~h}$ in $5 \% \mathrm{CO}_{2}$ at $37^{\circ} \mathrm{C}$. The EdU solution was then removed and replaced with staining fixative solution (cat. no. P0098; Beyotime Institute of Biotechnology) (1 ml/plate). The cells were fixed at room temperature for $15 \mathrm{~min}$, then washed three times with washing solution. Next, the cells were incubated with permeabilization solution (cat. no. P0097; Beyotime Institute of Biotechnology) (1 ml/plate) for $15 \mathrm{~min}$ at room temperature. The Click Reaction Buffer Solution (CuS04: Azide 594: Click Additive Solution=430:20:1:50) was configured according to the manufacturer's instructions. After being washed twice, $0.5 \mathrm{ml}$ of Click Reaction Buffer Solution was added to each of the culture plates, which were then incubated at room temperature for $30 \mathrm{~min}$ in the dark. Finally, Hoechst 33342 was used for nuclear staining; $1 \mathrm{ml}$ $1 \mathrm{X}$ Hoechst 33342 staining solution was added to each of the culture plates, which were then incubated at room temperature for $10 \mathrm{~min}$ in the dark. Images were captured using an upright fluorescence microscope (IX51; magnification, x200; Olympus Corporation).

Cell cycle detection. Cell cycle analysis was performed using the cell cycle and apoptosis detection kit (cat. no. C1052; Beyotime Institute of Biotechnology). DRG cells were digested using $0.25 \%$ trypsin and washed twice with PBS following the treatment of each group. The cells were resuspended with $75 \%$ cold ethanol and then fixed overnight at $4^{\circ} \mathrm{C}$ with $75 \%$ ethanol. The next day, cells were washed with cold PBS and dispersed to avoid cell agglomeration. Propidium iodide (PI) staining solution [0.5 ml staining buffer, $25 \mu 1$ PI (20X), $10 \mu 1$ RNase A $(50 \mathrm{X})]$ was added to the cell pellet $(0.5 \mathrm{ml} /$ tube). After being mixed, the cells were incubated at $37^{\circ} \mathrm{C}$ for $0.5 \mathrm{~h}$ in the dark. Finally, flow cytometry (NovoCyte; Agilent Technologies, Inc.) was used to detect the cell cycle distribution of each group.

Cell apoptosis detection. Apoptotic cells were quantified using an Annexin V/PI double staining kit (cat. no. BB-4101-2; BestBio Science) according to the manufacturer's instructions, and detected using a FACSCalibur flow cytometer (BD Biosciences). The apoptotic rate was analyzed using FlowJo software (v.7.6.1; BD Biosciences). Cells that stained positive for Annexin V and negative for PI were early apoptotic, whereas those that were positive for both were identified as late apoptotic cells. The apoptotic rates were expressed as the percentage of the total cell population.

Western blotting. Intracellular proteins from the DRG cells were extracted using RIPA lysis buffer (Thermo Fisher Scientific, Inc.), according to the manufacturer's protocol, for $30 \mathrm{~min}$ on ice. Then the cell debris was removed by centrifugation at $12,000 \mathrm{xg}$ for $5 \mathrm{~min}$ at $4^{\circ} \mathrm{C}$. The protein concentrations were determined using a bicinchoninic acid (BCA) protein assay kit (cat. no. P0010; Beyotime Institute of Biotechnology). Each group (30 $\mu \mathrm{g} / \mathrm{lane}$, volume/lane was kept the same by 
A
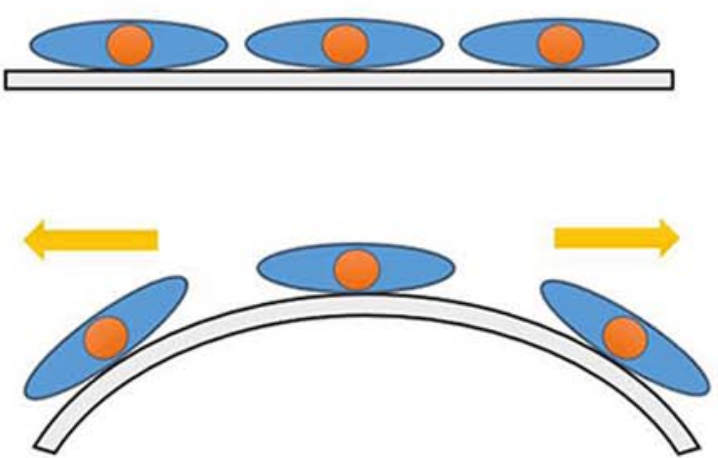

B

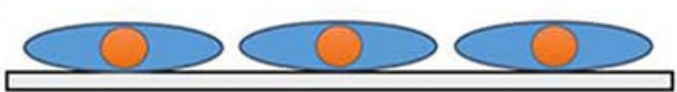

Figure 1. Principle of cell mechanics loading. (A) Cells were subjected to pulling force when the culture plate was forced upwardly convex. (B) Cells were under pressure when the culture plate was depressed downward.

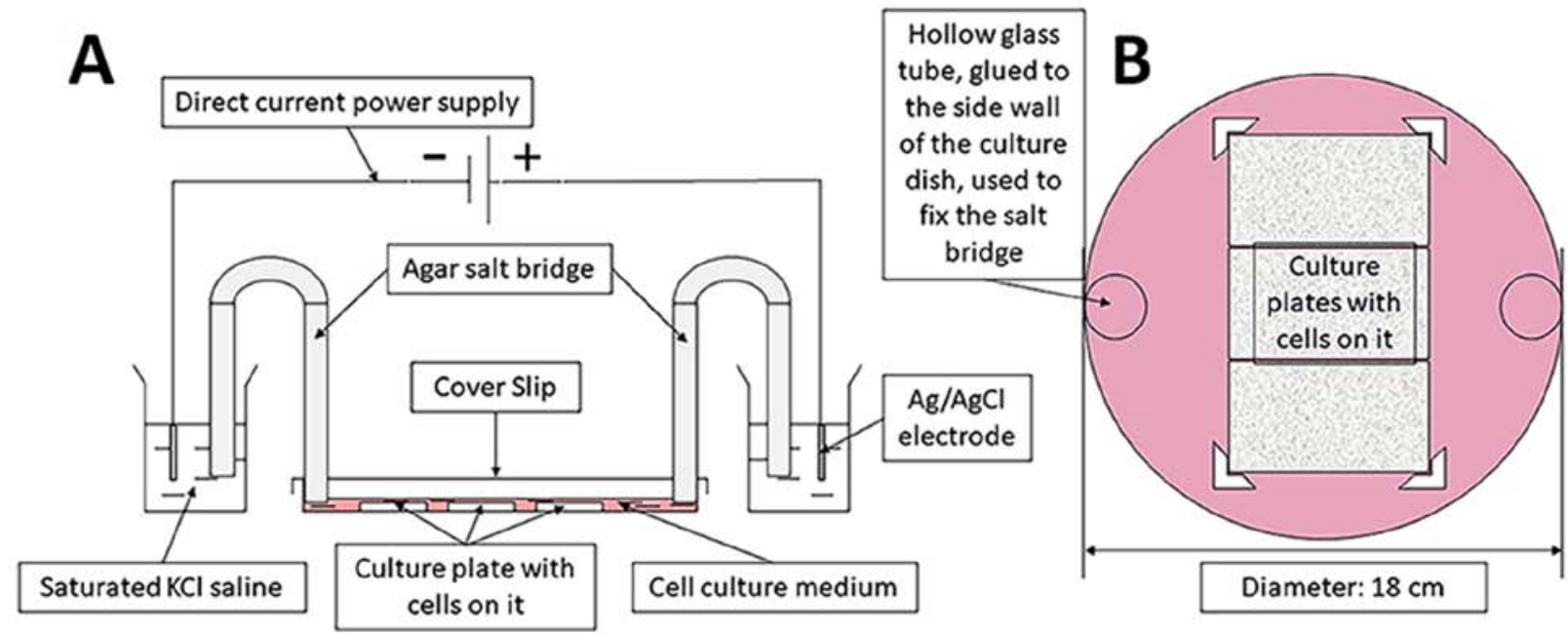

Figure 2. Schematic diagram of electrical stimulation device. (A) Overall device composition. (B) Internal stimulation diagram of electrical stimulation circular culture dish.

using loading buffer) was separated by $10 \%$ SDS-PAGE gel electrophoresis and transferred to PVDF membranes. Following blocking with 5\% skimmed milk powder for $1 \mathrm{~h}$ at room temperature, primary antibodies for $\beta$-catenin (1:1,000; cat. no. ab32572; Abcam), glycogen synthase kinase (GSK)-3 $\beta$ (1,1,000; cat. no. 12456S; Cell Signaling Technology, Inc.), Bax (1,2000; cat. no. ab182733; Abcam), Bcl-2 (1:1,000; cat. no. ab32124; Abcam), C-myc (1;1,000; cat. no. ab32072; Abcam) and $\beta$-actin $(1: 1,000$; cat. no. GB11001; Wuhan Servicebio Technology Co., Ltd.) were added prior to incubation overnight at $4^{\circ} \mathrm{C}$. The next day, bands were washed using TBS containing $0.05 \%$ Tween and incubated with fluorescently labeled secondary antibody (IRDye $800 \mathrm{CW}$; goat anti-mouse/rabbit; 1:10,000; cat. nos. 926-32280 and 926-32211; LI-COR Biosciences) at room temperature for $1 \mathrm{~h}$. Protein bands were scanned using an Odyssey far infrared imaging system (LI-COR Biosciences) and analyzed using Quantity One software v.4.6.2 (Bio-Rad Laboratories, Inc.). $\beta$-actin was used as the internal control.

XAV939 treatment. XAV939, an inhibitor of the Wnt signaling pathway, was purchased from Selleck Chemicals (cat. no. S1180). The $10 \mathrm{mmol} / \mathrm{l}$ storage solution was diluted to $1 \mu \mathrm{mol} / 1$ working solution with DMEM, supplemented with $15 \%$ FBS, $100 \mathrm{U} / \mathrm{ml}$ penicillin $\mathrm{G}$ and $100 \mu \mathrm{g} / \mathrm{ml}$ streptomycin. Cells were pre-treated with $1 \mu \mathrm{mol} / 1 \mathrm{XAV} 939$ at room temperature for $\sim 5$ min prior to being treated with CMS or ES immediately to determine cell proliferation as previously described.

Statistical analysis. Statistical analyses were performed using GraphPad Prism (version 7.0; GraphPad Software, Inc.), and data are presented as the mean \pm standard deviation. Groups were compared using one-way analysis of variance. Differences between two groups were determined using Student's t-test and multiple means were compared using Tukey's test. $\mathrm{P}<0.05$ was considered to indicate a statistically significant difference. Each experiment was repeated at least three times.

\section{Results}

ES promotes the viability of injured DRG cells. CCK-8 assays were used to detect cell viability under different intervention conditions. DRG cells in the ES group underwent ES $(100 \mathrm{mV} / \mathrm{mm} ; 1 \mathrm{~h})$, in accordance with a previous 


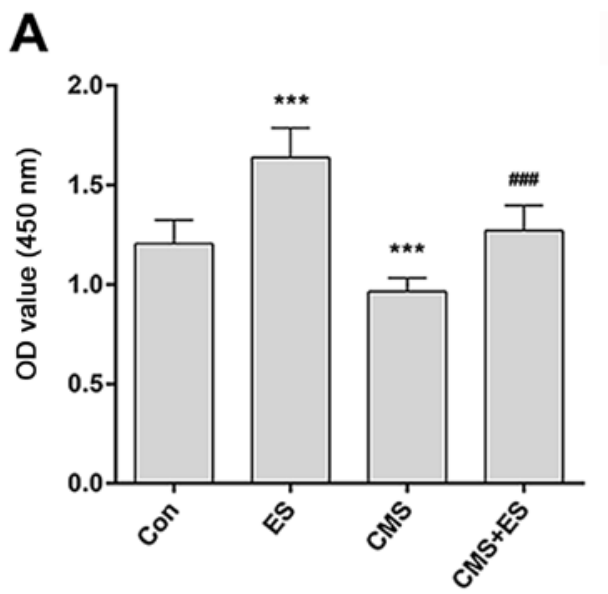

B
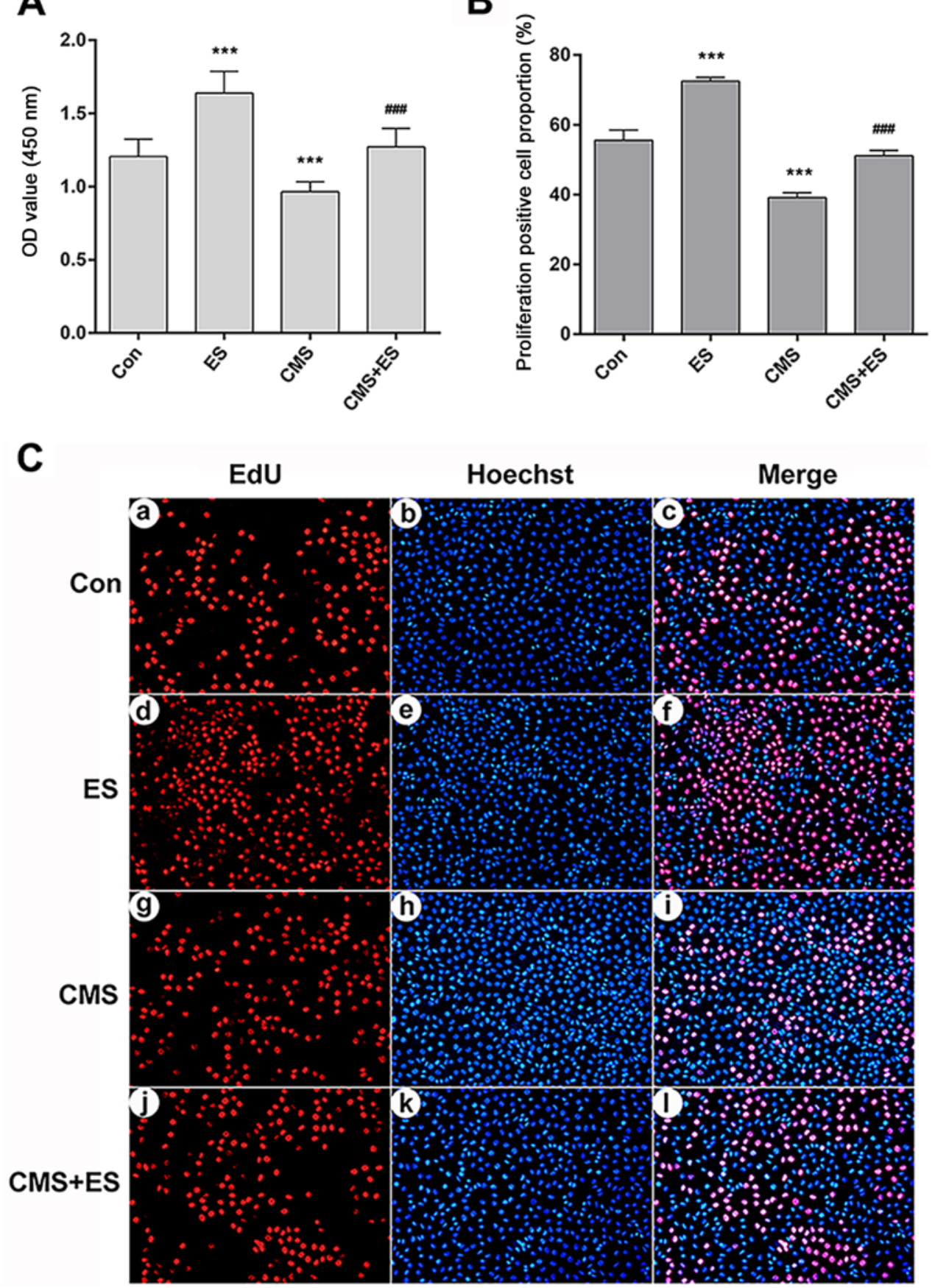

Figure 3. Influences of ES on the viability of injured DRG cells. (A) Cell viability analyzed using the OD value. (B) Quantitative analysis of the proportion of EdU-positive proliferating DRG cells. (C) EdU staining (magnifcation, $x 200$ ). Red fluorescence represents proliferation-positive cells (a, d, $g$, $j$ represent the control, ES, CMS and CMS + ES groups respectively), and blue fluorescence represents the nuclei of all cells in view (b, e, h, k represent the control, ES, CMS and CMS + ES groups respectively). Pink cells in the merged images are proliferation-positive cells (c, f, i, 1 represent the control, ES, CMS and CMS + ES groups respectively). Each set of experiments was repeated three times. Data are expressed as the mean \pm standard deviation. ${ }^{* * * *} \mathrm{P}<0.001 \mathrm{vs.} \mathrm{Con;}$ ${ }^{\# \# \# P<0.001 ~ v s . ~ C M S ~ g r o u p . ~ E S, ~ e l e c t r i c a l ~ s t i m u l a t i o n ; ~ D R G, ~ d o r s a l ~ r o o t ~ g a n g l i o n ; ~ C o n, ~ c o n t r o l ; ~ C M S, ~ c y c l i c ~ m e c h a n i c a l ~ s t r e s s ; ~ O D, ~ o p t i c a l ~ d e n s i t y ; ~ E d U, ~}$ 5-ethynyl-2'-deoxyuridine.

study (28). Cells in the CMS group were subjected to CMS [1 Hz; $8 \mathrm{~h} ; 5,333 \mu(4 \mathrm{~mm})]$ (26). In the CMS + ES group, DRG cells were treated with CMS, and then immediately placed in the ES device for ES treatment. The OD values at $450 \mathrm{~nm}$ of the control, ES, CMS and CMS + ES groups were $1.21 \pm 0.12,1.64 \pm 0.15,0.97 \pm 0.07$ and $1.27 \pm 0.12$, respectively. Compared with the control group, the cell activity of the ES group was significantly increased whereas the cell activity of the CMS group was significantly decreased $(\mathrm{P}<0.001)$. In the CMS + ES group, the cell viability was significantly increased compared with that in the CMS group $(\mathrm{P}<0.001$; Fig. 3A).

The proliferation of DRG cells was detected using EdU-594 cell proliferation assay kit. EdU is a novel thymidine analogue that replaces thymidine in newly synthesized DNA during DNA synthesis. The Azide Alexa Fluor 594 probe covalently 

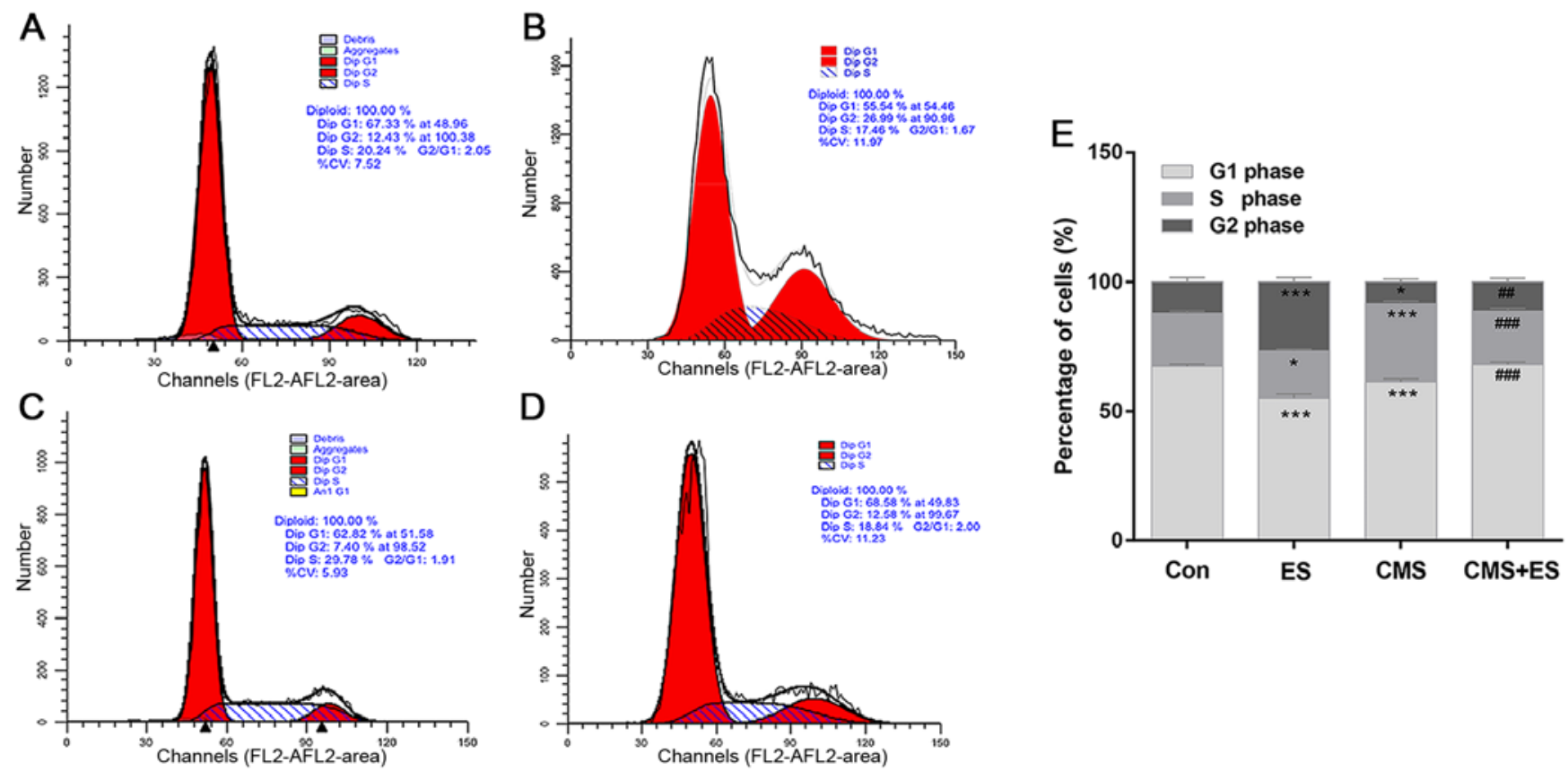

Figure 4. Effect of ES on DRG cell cycle distribution. Flow cytometry cell cycle results of (A) Con, (B) ES, (C) CMS and (D) CMS + ES groups. (E) Quantitative analysis of cell cycle phases proportion. Data are expressed as the mean \pm standard deviation. Each set of experiments is repeated three times. ${ }^{*} \mathrm{P}<0.05$, ${ }^{* * *} \mathrm{P}<0.001$ vs. Con; ${ }^{\# \#} \mathrm{P}<0.01,{ }^{\# \# \#} \mathrm{P}<0.001$ vs. CMS group. ES, electrical stimulation; DRG, dorsal root ganglion; CMS, cyclic mechanical stretching; Con, control.

reacts with the acetylene group of EdU, which ensures direct and accurate detection of proliferating cells. Hoechst 33342 was used for nuclear staining. Following treatment, healthy DRG cells would show a normal blue nucleus under a fluorescence microscope, whereas the nuclei of apoptotic cells would be stained white. Both blue and red fluorescence showed the nucleus, where blue represented all DRG cells in the field of view, and red represented the proliferating cells (Fig. 3C). A total of three fields of view were randomly selected from each group of cells, and the positive rates of cell proliferation were then counted. The proliferating cell proportion of the control, $\mathrm{ES}, \mathrm{CMS}$ and CMS + ES groups were 55.55 $\pm 2.96,72.51 \pm 1.10$, $39.17 \pm 1.34$ and $51.13 \pm 1.54 \%$, respectively. The proportion of positive proliferating DRG cells was significantly increased, whereas this proportion in the CMS group was significantly decreased compared with the control group $(\mathrm{P}<0.001)$. Furthermore, the rate of cell proliferation in the CMS + ES group was higher than that of the CMS group $(\mathrm{P}<0.001$; Fig. 3B).

ES reverses CMS-induced cell cycle arrest and decreases DRG cell apoptosis. Flow cytometry was used to detect cell cycle and cell apoptosis. The present study demonstrated that the number of DRG cells in the G2 phase in the ES group was significantly increased compared with the control group $(\mathrm{P}<0.001)$. The number of cells in the $S$ phase of the $C M S$ group was significantly higher than that of the control group $(\mathrm{P}<0.001)$. Furthermore, the number of cells in the $\mathrm{S}$ phase in the CMS + ES group was significantly lower than that in the CMS group $(\mathrm{P}<0.001)$, and the number of cells in the G2 phase was significantly increased $(\mathrm{P}<0.01$; Fig. 4 and Table I). These changes indicated that ES has significant roles in promoting the progression of the cell cycle in normal DRG cells. In addition, CMS arrested DRG cells in the $\mathrm{S}$ phase, which impeded cell cycle progression. However, the results of the present study indicate that this process may be reversed following ES treatment.

Cells that stained positive for Annexin $\mathrm{V}$ and negative for PI (Annexin V-FITC ${ }^{+} / \mathrm{PI}^{-}$) were early apoptotic, whereas those that stained positive for both (Annexin $\mathrm{V}-\mathrm{FITC}^{+} / \mathrm{PI}^{+}$) were late apoptotic. The present study demonstrated that the apoptosis rate of the CMS group was significantly higher than that of the control group $(\mathrm{P}<0.001)$, whereas the total apoptotic rate of the ES group was significantly lower compared with the control group $(\mathrm{P}<0.001)$. Moreover, the apoptosis rate of DRG cells in the CMS + ES group was decreased compared with the CMS group $(\mathrm{P}<0.001$; Fig. 5 and Table II). These results were consistent with the results of the cell viability and cell cycle findings in the present study, confirming the promotive effects of ES on DRG cells.

Effect of ES on the expression levels of Wnt/ $\beta$-catenin pathway-associated proteins in injured DRG cells. The expression levels of $\beta$-catenin, Bcl-2 and $\mathrm{C}$-myc increased following ES treatment $(\mathrm{P}<0.05$ and $\mathrm{P}<0.001)$, and the expression levels of these three proteins in the CMS group were significantly decreased $(\mathrm{P}<0.001)$ in comparison with those in the control group. The present study demonstrated that the expression levels of $\beta$-catenin, $\mathrm{Bcl}-2$ and $\mathrm{C}$-myc in the CMS + ES group were also increased compared with those in the CMS group, and that these differences were statistically significant $(\mathrm{P}<0.05$ and $\mathrm{P}<0.001$; Fig. 6A, B, E and $\mathrm{F})$. In contrast, the expression levels of GSK-3 $\beta$ and Bax in the ES group were lower than those in the control group $(\mathrm{P}<0.05)$, and the expression levels of these two proteins in the CMS group were significantly increased $(\mathrm{P}<0.001)$. Furthermore, the expression levels of GSK-3 $\beta$ and Bax in the CMS + ES 
Table I. Effects of ES on cell cycle of DRG cells.

\begin{tabular}{lccc}
\hline Group & G0/G1 phase, $\%$ & S phase, $\%$ & G2 phase, $\%$ \\
\hline Con & $67.47 \pm 0.76$ & $20.40 \pm 0.96$ & $12.13 \pm 1.71$ \\
ES & $55.01 \pm 1.69^{\mathrm{b}}$ & $18.24 \pm 0.68^{\mathrm{a}}$ & $26.75 \pm 1.65^{\mathrm{b}}$ \\
CMS & $61.45 \pm 1.07^{\mathrm{b}}$ & $30.02 \pm 0.99^{\mathrm{b}}$ & $8.53 \pm 1.08^{\mathrm{a}}$ \\
CMS + ES & $68.12 \pm 1.00^{\mathrm{d}}$ & $19.58 \pm 1.03^{\mathrm{d}}$ & $12.30 \pm 0.55^{\mathrm{c}}$ \\
F-value & 107.50 & 134.90 & 146.20 \\
P-value & $<0.001$ & $<0.001$ & $<0.001$ \\
\hline
\end{tabular}

${ }^{\mathrm{a}} \mathrm{P}<0.05,{ }^{\mathrm{b}} \mathrm{P}<0.001$ vs. Con; ${ }^{\mathrm{c}} \mathrm{P}<0.01,{ }^{\mathrm{d}} \mathrm{P}<0.001$ vs. CMS group. ES, electrical stimulation; DRG, dorsal root ganglion; Con, control; CMS, cyclic mechanical stretching.

A

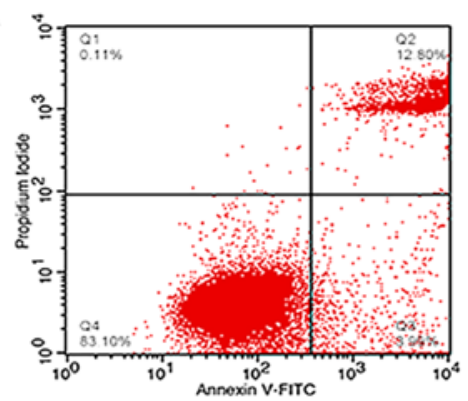

C

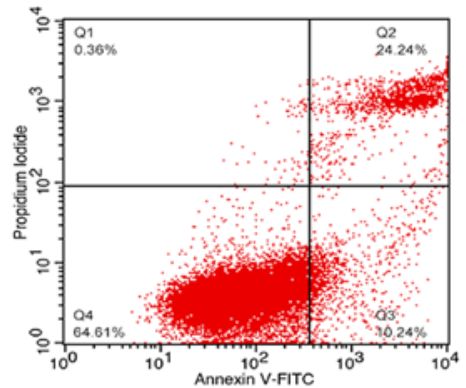

B

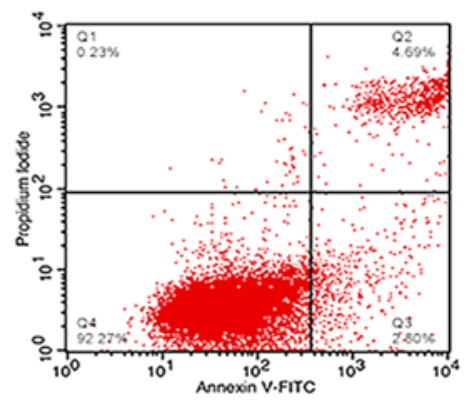

D

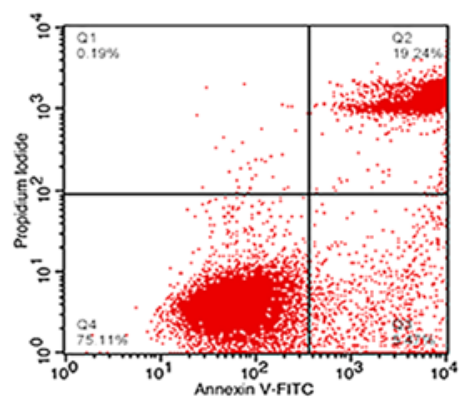

$\mathbf{E}$

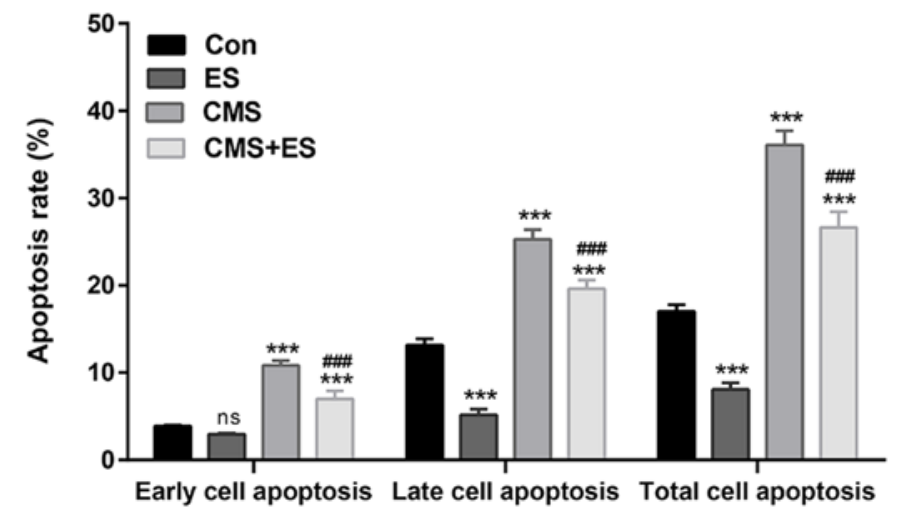

Figure 5. Effect of ES on DRG cell apoptosis. Flow cytometry apoptosis results of (A) Con, (B) ES, (C) CMS and (D) CMS + ES groups. (E) Quantitative analysis of cell apoptosis rate. Each set of experiment was repeated three times. Data are expressed as the mean \pm standard deviation. ${ }^{* * *} \mathrm{P}<0.001$ vs. Con;

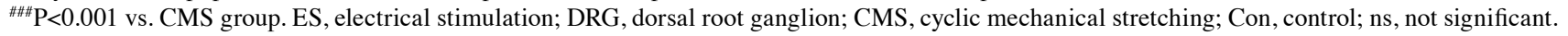

group were decreased compared with those in the CMS group (P<0.05; Fig. 6A, C and D).

Wnt/ $\beta$-catenin pathway is potentially involved in the influence of ES over injured DRG cells. It was hypothesized that the $\mathrm{Wnt} / \beta$-catenin signaling pathway was involved in the process by which ES affects DRG cells because of the detected protein changes associated with the $\mathrm{Wnt} / \beta$-catenin pathway. The present study used the $\mathrm{Wnt} / \beta$-catenin pathway inhibitor XAV939 at a concentration of $1 \mu \mathrm{mol} / 1$, which did not affect DRG cell viability by itself (Fig. 7). The present study demonstrated that DRG cells in the ES group showed a significant 
Table II. Effects of ES on cell apoptosis of DRG cells.

\begin{tabular}{lccr}
\hline Group & Annexin V+/PI-Early apoptosis, $\%$ & Annexin V+/PI+Late apoptosis, $\%$ & Total apoptosis, $\%$ \\
\hline Con & $3.860 \pm 0.110$ & $13.140 \pm 0.730$ & $17.010 \pm 0.780$ \\
ES & $2.920 \pm 0.130^{\mathrm{a}}$ & $5.170 \pm 0.640^{\mathrm{b}}$ & $8.090 \pm 0.740^{\mathrm{b}}$ \\
CMS & $10.837 \pm 0.524^{\mathrm{b}}$ & $25.263 \pm 1.132^{\mathrm{b}}$ & $36.100 \pm 1.610^{\mathrm{b}}$ \\
CMS + ES & $6.980 \pm 0.940^{\mathrm{b}, \mathrm{c}}$ & $19.640 \pm 0.960^{\mathrm{b}, \mathrm{c}}$ & $26.620 \pm 1.820^{\mathrm{b}, \mathrm{c}}$ \\
F-value & 128.800 & 285.600 & 247.900 \\
P-value & $<0.001$ & $<0.001$ & $<0.001$
\end{tabular}

${ }^{\mathrm{a}} \mathrm{P}>0.05$ vs. Con (not significant); ${ }^{\mathrm{b}} \mathrm{P}<0.001$ vs. Con; ${ }^{\mathrm{c}} \mathrm{P}<0.001$ vs. CMS group. ES, electrical stimulation; DRG, dorsal root ganglion; Con, control; CMS, cyclic mechanical stretching.

A

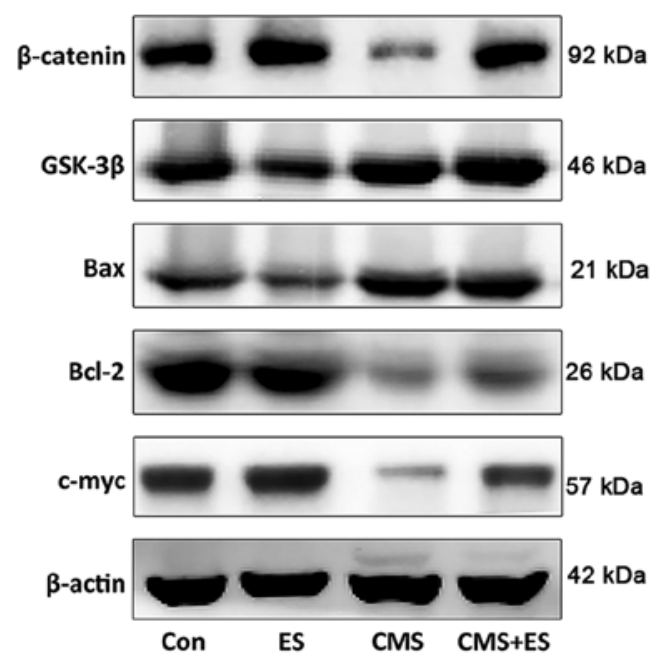

B
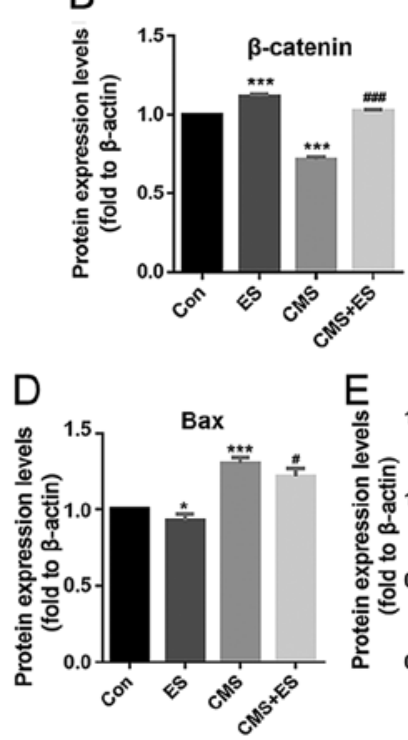
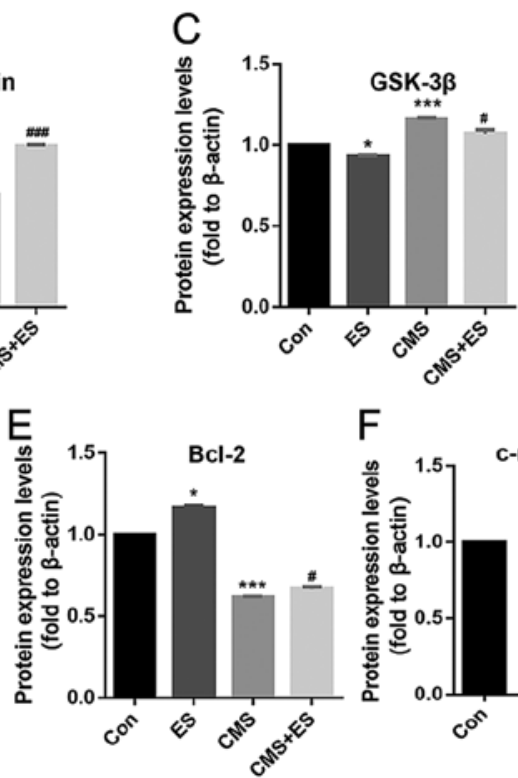

$\mathrm{F}$

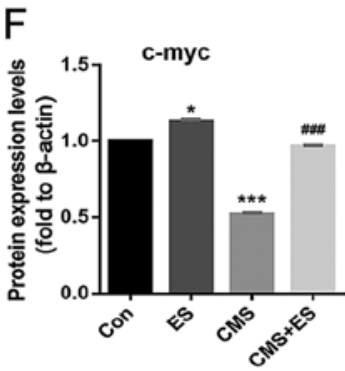

Figure 6. Effect of ES on the expression levels of Wnt/ $\beta$-catenin pathway-related proteins in injured DRG cells. (A) Representative blots of $\beta$-catenin, Bax, Bcl-2 and C-myc. Quantitative analysis of protein expression levels of (B) $\beta$-catenin, (C) GSK-3 $\beta$, (D) Bax, (E) Bcl-2 and (F) C-myc. Each set of experiments was repeated three times. Data are expressed as the mean \pm standard deviation. ${ }^{*} \mathrm{P}<0.05,{ }^{* * * *} \mathrm{P}<0.001$ vs. Con; ${ }^{\#} \mathrm{P}<0.05$, ${ }^{\# \# \#} \mathrm{P}<0.001$ vs. CMS group. ES, electrical

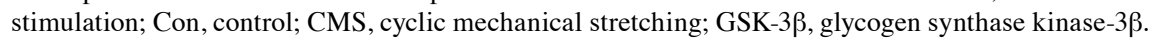

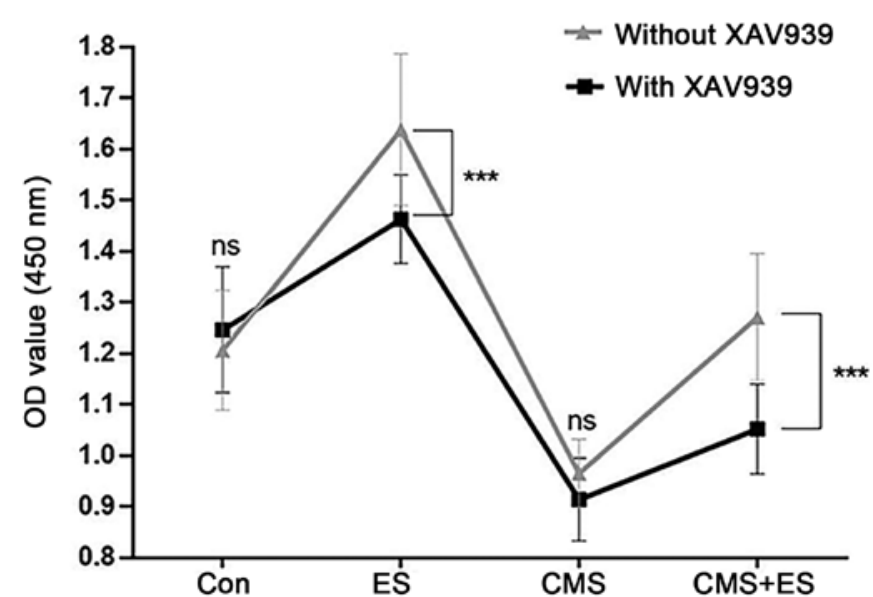

Figure 7. Influences of ES on the viability of DRG cells following treatment with XAV939. Each set of experiment was repeated three times. Data are expressed as the mean \pm standard deviation. ${ }^{* * *} \mathrm{P}<0.001$. ES, electrical stimulation; DRG, dorsal root ganglion; Con, control; CMS, cyclic mechanical stretching; ns, not significant. decrease in activity following administration of XAV939, and similar changes were observed in the CMS + ES group $(\mathrm{P}<0.001)$. However, following exposure to XAV939, the cell activity in the CMS + ES group was still slightly increased compared with the CMS group $(\mathrm{P}<0.001)$, indicating that other pathways may regulate the effects of ES on DRG cells, although this requires verification in future studies (Fig. 7).

\section{Discussion}

With the increasing trend towards an aging population, the incidence of SUI is increasing by $4-10 \%$ per year globally (1). The multi-center large sample survey conducted by Zhu et al (3) demonstrated that the overall incidence of urinary incontinence is $30.9 \%$, of which SUI accounts for $61 \%$, among 19,024 female subjects. Therefore, research regarding the etiology and treatment of SUI may have important applications. Clinically, PES treatment has a significant effect on patients with mild-to-moderate SUI symptoms: Its cure rate is $30-60 \%$, 
and its improvement rate is $60-90 \%$ (6-8). To the best of our knowledge, however, the mechanism of PES in the treatment for SUI has not previously been identified. Stretching injury of pelvic floor nerves, muscles and connective tissue caused by pregnancy and vaginal delivery are major risk factors for SUI (29). Delancey (11) proposed that PN injury causes denervation of pelvic floor muscles. Previous studies of pelvic floor electromyography of patients with SUI, nerve conduction velocity, pelvic floor muscle pathology and neurofibrillary immunohistochemical staining have also demonstrated that pelvic denervation is present in patients with SUI $(9,30,31)$. These studies indicate that PN injury is important in the pathogenesis of SUI. In studies of neurological diseases, ES has been demonstrated to promote synaptic repair, nerve cell growth and regeneration (12-14) Therefore, it was hypothesized that the therapeutic effect of PES in the treatment of SUI was achieved by promoting the repair of injured PNs.

Culturing nerve cells in vitro provides a basis for the study of nerve cells at the molecular and cellular levels. Nerve cells in DRGs are widely used in neuroscience research, particularly in the study of peripheral nerve injury and peripheral neuropathy (32-34). Therefore, the present study used DRG cells. In addition, it has been demonstrated that PN injury in SUI is primarily caused by nerve traction injury during pregnancy and childbirth $(29,35,36)$. In order to simulate this phenomenon at the cellular level, DRG cells were subjected to CMS. A number of studies have constructed cell traction injury models by mechanical stretching or deformation by applying pressure to cells $(37,38)$. Our previous studies have also constructed a fibroblast model by CMS successfully, which demonstrated that CMS can simulate traction injury in fibroblasts (39-41). In addition, our previous study subjected DRG cells to CMS and demonstrated that the DRG injury could be best simulated under the parameters of 5,333 $\mu$ strain $(4 \mathrm{~mm}), 8 \mathrm{~h}$ and $1 \mathrm{~Hz}(26)$, which was used in the present study. There are two main methods of applying ES to cells: Direct ES and indirect ES (42). The salt bridge system used in the present study could directly stimulate DRG cells in order to simulate pudendal nerve electrical stimulation, which is a direct ES method clinically.

The present study established CMS and ES models in DRG cells. The present study demonstrated that ES of $100 \mathrm{mV} / \mathrm{mm}$ for $1 \mathrm{~h}$ increased the proliferative activity of untreated DRG cells. In addition, CMS of 5,333 $\mu$ strain for $8 \mathrm{~h}$ significantly decreased cell proliferation activity, which was attenuated by ES of $100 \mathrm{mV} / \mathrm{mm}$ for $1 \mathrm{~h}$. These results demonstrated that ES may alleviate damage to DRG cells caused by mechanical force. The present study also measured changes in the cell cycle distribution and apoptosis of DRG cells. The cell cycle is regulated by two phase transition points, G1/S and G2/M. In the present study, the proportion of cells in the G2 phase significantly decreased in the CMS group, whereas the proportion of cells in the $\mathrm{S}$ phase and the apoptosis rate increased. Combined with the detection of cell activity, the present study demonstrated that CMS blocked the DRG cell cycle in the S phase, blocked cell mitosis and ultimately led to cell apoptosis. ES decreased the proportion of cells in the S phase, increased the proportion of cells in the G2 phase, advanced cell cycle progression and decreased the rate of apoptosis.

A number of studies have confirmed that the Wnt/ $\beta$-catenin classical signaling pathway is closely associated with the nervous system, and is involved in the processes of proliferation and differentiation of neural stem cells and axonal formation (43-45). Previous studies have demonstrated that ES treatment alters the expression levels of Wnt pathway-associated factors (18) and regulates directional migration of neural cells (19). The present study therefore investigated the expression levels of these proteins. The present study demonstrated that CMS increased the expression level of GSK-3 $\beta$ protein, decreased the expression levels of $\beta$-catenin protein and inhibited the Wnt/ $\beta$-catenin pathway, whereas ES decreased GSK-3 $\beta$, increased $\beta$-catenin, and further activated the Wnt $/ \beta$-catenin signaling pathway. This indicated that both CMS and ES have effects on the classical Wnt/ $\beta$-catenin pathway.

$\mathrm{C}$-myc protein is an important downstream molecule of the Wnt/ $\beta$-catenin signaling pathway and is consistent with the expression level of $\beta$-catenin (46). In addition, the Bcl- 2 family plays an important role in apoptosis. Bcl-2, an anti-apoptotic gene, plays an antagonistic role with Bax, a pro-apoptotic gene, in the apoptosis process (47). The present study demonstrated that in the CMS group, the expression levels of $\mathrm{Bcl}-2$ protein decreased and the expression levels of Bax protein increased, inducing the apoptosis of DRG cells. Conversely, the expression levels of Bcl-2 protein increased and the expression levels of Bax protein decreased when DRG cells were subjected to ES. These results indicated that the Wnt/ $/$-catenin signaling pathway may be involved in the process by which ES promotes the cell viability of DRG cells.

The present study used XAV939, an inhibitor of Wnt, to investigate the role of $\mathrm{Wnt} / \beta$-catenin signaling. The present study demonstrated that the cell proliferation activity promoted by ES was partly inhibited following administration of XAV939. This indicated that the Wnt signaling pathway may be involved in the activation of DRG cells by ES. Further research is required to identify other pathways that may be involved in this process. Meanwhile, it was previously demonstrated that the expression levels of caspase- 3 in injured DRG cells treated with ES were significantly decreased (48). Caspase is a classical apoptosis-associated factor. Future studies will investigate how it participates in the regulation of ES and CMS on DRG cells.

Although PES is a clinically effective means of SUI treatment, little is currently known regarding its molecular mechanisms. The present study demonstrated the protective effect of ES on DRG cells with CMS-induced injury at the cellular level. ES may promote the proliferative activity of DRG cells, reverse $\mathrm{S}$ phase arrest and limit the CMS-induced increase in the rate of apoptosis. Furthermore, both CMS and ES exerted effects on the classical Wnt/ $\beta$-catenin pathway, and also affected the expression levels of downstream proteins, which indicated that the Wnt/ $\beta$-catenin signaling pathway may be involved in the response of DRG cells to CMS and ES. The present study therefore provides a theoretical basis to further investigate the specific mechanism of ES in the treatment of SUI.

\section{Acknowledgements}

The authors would like to thank Dr Lijuan Gu, Dr Lina Zhou and Mrs. Yingxia Jin of the Central Laboratory of Renmin Hospital of Wuhan University for their experimental and technical support and discussions of the manuscript. 


\section{Funding}

The present study was supported by the National Natural Science Foundation of China (grant no. 81771562) and the Chinese Women's Pelvic Floor Dysfunction Prevention Project of Chinese Preventive Medicine Association (grant no. 201817092).

\section{Availability of data and materials}

The datasets used and/or analyzed during the present study are available from the corresponding author on reasonable request.

\section{Authors' contributions}

MH performed the majority of the experiments and drafted the manuscript; SH, GH, YC and QC helped perform the experiments and analyze the data; and $\mathrm{MH}$ and $\mathrm{LH}$ conceived the study, supervised the experiments and edited the manuscript. All authors read and approved the final manuscript.

\section{Ethics approval and consent to participate}

Not applicable.

\section{Patient consent for publication}

Not applicable.

\section{Competing interests}

The authors declare that they have no competing interests.

\section{References}

1. Reynolds WS, Dmochowski RR and Penson DF: Epidemiology of stress urinary incontinence in women. Curr Urol Rep 5 : 370-376, 2011

2. Fultz NH and Herzog AR: Self-reported social and emotional impact of urinary incontinence. J Am Geriatr Soc 49: 892-899, 2010

3. Zhu L, Lang JH, Liu CY, Han SM, Huang JS and Li XM: The epidemiological study of women with urinary incontinence and risk factors for stress urinary incontinence in China. Menopause 107 (Suppl): S236, 2009.

4. Chong EC, Khan AA and Anger JT: The financial burden of stress urinary incontinence among Women in the United States. Curr Urol Rep 12: 358-362, 2011.

5. Wilson L, Brown JS, Shin GP, Luc KO and Subak LL: Annual direct cost of urinary incontinence. Obstetrics Gynecol 98: 398-406, 2001.

6. Jeyaseelan SM and Oldham JA: Electrical stimulation as a treatment for stress incontinence. Br J Nurs 9: 1001, 2000.

7. Jeyaseelan SM, Haslam EJ, Winstanley J, Roe BH and Oldham JA: An evaluation of a new pattern of electrical stimulation as a treatment for urinary stress incontinence: A randomized, double-blind, controlled trial. Clin Rehabil 14: 631-640, 2000.

8. Indrekvam S, Sandvik H and Hunskaar S: A Norwegian national cohort of 3198 women treated with home-managed electrical stimulation for urinary incontinence-effectiveness and treatment results. Scand J Urol Nephrol 35: 32-39, 2001.

9. Zhu L, Lang J, Chen J and Chen J: Study on nerve fiber density in anterior vaginal epithelium for stress urinary incontinence. Int Urogynecol J Pelvic Floor Dysfunct 15: 272-275, 2004.

10. Yoshida S, Koyama M, Kimura T, Murakami G, Niikura H, Takenaka A and Murata Y: A clinicoanatomical study of the novel nerve fibers linked to stress urinary incontinence: The first morphological description of a nerve descending properly along the anterior vaginal wall. Clin Anat 20: 300-306, 2010.
11. Delancey JO: Anatomy and biomechanics of genital prolapse. Clin Obstetrics Gynecol 136: 897-909, 1993.

12. Liu Y, Grumbles RM and Thomas CK: Electrical stimulation of embryonic neurons for 1 hour improves axon regeneration and the number of reinnervated muscles that function. J Neuropathol Exp Neurol 72: 697-707, 2013.

13. Gordon T, Udina E, Verge VM and de Chaves EI: Brief electrical stimulation accelerates axon regeneration in the peripheral nervous system and promotes sensory axon regeneration in the central nervous system. Motor Control 13: 412-441, 2009.

14. Boggio PS, Valasek CA, Campanhã C, Giglio AC, Baptista NI, Lapenta OM and Fregni F: Non-invasive brain stimulation to assess and modulate neuroplasticity in Alzheimer's disease. Neuropsychol Rehabil 21: 703-716, 2011.

15. Ille F and Sommer L: Wnt signaling: Multiple functions in neural development. Cell Mol Life Sci 62: 1100-1108, 2005.

16. David MD, Cantí C and Herreros J: Wnt-3a and Wnt-3 differently stimulate proliferation and neurogenesis of spinal neural precursors and promote neurite outgrowth by canonical signaling. J Neurosci Res 88: 3011-3023, 2010.

17. Suh HI, Min J, Choi KH, Kim SW, Kim KS and Jeon SR: Axonal regeneration effects of Wnt3a-secreting fibroblast transplantation in spinal cord-injured rats. Acta Neurochir 153: 1003-1010, 2011.

18. Wu Y, Collier L, Qin W, Creasey G, Bauman WA, Jarvis J and Cardozo C: Electrical stimulation modulates Wnt signaling and regulates genes for the motor endplate and calcium binding in muscle of rats with spinal cord transection. BMC Neurosci 14: $81,2013$.

19. Liu J, Zhu B, Zhang G, Wang J, Tian W, Ju G, Wei X and Song B: Electric signals regulate directional migration of ventral midbrain derived dopaminergic neural progenitor cells via Wnt/GSK3 $\beta$ signaling. Exp Neurol 263: 113-121, 2015.

20. Zhang K, Guo J, Ge Z and Zhang J: Nanosecond pulsed electric fields (nsPEFs) regulate phenotypes of chondrocytes through Wnt/ß-catenin signaling pathway. Sci Rep 4: 5836, 2014.

21. Hunter T and Pines J: Cyclins and cancer II: Cyclin D and CDK inhibitors come of age. Cell 79: 573-582, 1994.

22. Cancer Genome Atlas Network; Muzny DM, Bainbridge MN Chang K, Dinh HH, Drummond JA, Fowler G, Kovar CL, Lewis LR, Morgan MB, et al: Comprehensive molecular characterization of human colon and rectal cancer. Nature 487: 330-337, 2012.

23. Wang H, Wang H, Makki MS, Wen J, Dai Y, Shi Q, Liu Q, Zhou X and Wang $\mathrm{J}$ : Overexpression of $\beta$-catenin and cyclinD1 predicts a poor prognosis in ovarian serous carcinomas. Int J Clin Exp Pathol 7: 264-271, 2013.

24. Lei ZJ, Wang J, Xiao HL, Guo Y, Wang T, Li Q, Liu L, Luo X, Fan LL, Lin L, et al: Lysine-specific demethylase 1 promotes the stemness and chemoresistance of Lgr5+ liver cancer initiating cells by suppressing negative regulators of $\beta$-catenin signaling. Oncogene 34: 3214, 2015.

25. Wu S, Guo Z, Hopkins CD, Wei N, Chu E, Wipf P and Schmitz JC: Bis-cyclopropane analog of disorazole $\mathrm{Cl}$ is a microtubule-destabilizing agent active in ABCB1-overexpressing human colon cancer cells. Oncotarget 6: 40866-40879, 2015.

26. Zhou M, Hu M, He S, Li B, Liu C, Min J and Hong L: Effects of rsc96 schwann cell-derived exosomes on proliferation, senescence, and apoptosis of dorsal root ganglion cells in vitro. Med Sci Monit 24: 7841-7849, 2018.

27. Song B, Gu Y, Pu J, Reid B, Zhao Z and Zhao M: Application of direct current electric fields to cells and tissues in vitro and modulation of wound electric field in vivo. Nat Protoc 2: 1479-1489, 2007.

28. Hu M, Hong L, Liu C, Hong S, He S, Zhou M, Huang G and Chen Q: Electrical stimulation enhances neuronal cell activity mediated by Schwann-cell-derived exosomes. Sci Rep 9: 4206, 2019.

29. Clark MH, Scott M, Vogt V and Benson JT: Monitoring pudendal nerve function during labor. Obstet Gynecol 97: 637-639, 2001.

30. Bakas P, Liapis A, Karandreas A and Creatsas G: Pudendal nerve terminal motor latency in women with genuine stress incontinence and prolapse. Gynecol Obstet Invest 51: 187-190, 2001.

31. Weidner AC, Barber MD, Visco AG, Bump RC and Sanders DB: Pelvic muscle electromyography of levator ani and external anal sphincter in nulliparous women and women with pelvic floor dysfunction. Am J Obstet Gynecol 183: 1390-1401, 2000.

32. Wood MD and Willits RK: Applied electric field enhances DRG Neurite growth: Influence of stimulation media, surface coating and growth supplements. J Neural Eng 6: 46003, 2009.

33. Stewart AL, Anderson RB, Kobayashi K and Young HM: Effects of NGF, NT-3 and GDNF family members on neurite outgrowth and migration from pelvic ganglia from embryonic and newborn mice. BMC Dev Biol 8: 73, 2008. 
34. Zhang W, Hu Y, Newman EA and Mulholland MW: Serum-free culture of rat postnatal neurons derived from the dorsal motor nucleus of the vagus. J Neurosci Meth 150: 1-7, 2006.

35. Lien KC, Morgan DM, Delancey JO and Ashton-Miller JA: Pudendal nerve stretch during vaginal birth: A 3D computer simulation. Am J Obstet Gynecol 192: 1669-1676, 2005.

36. Efrat H, Asnat G, Ronen G, Joseph L and David G: Pregnancy, labor and delivery: The pelvic floor injury. Harefuah 143: 525-529, 547, 548, 2004.

37. Ellis EF, Mckinney JS, Willoughby KA, Liang S and Povlishock JT: A new model for rapid stretch-induced injury of cells in culture: Characterization of the model using astrocytes. J Neurotrauma 12: 325-339, 1995.

38. Morrison B III, Meaney DF and McIntosh TK: mechanical characterization of an in vitro device designed to quantitatively injure living brain tissue. Ann Biomed Eng 26: 381-390, 1998.

39. Hu M, Hong L, Hong S, Min J, Zhao Y, Yang Q, Zhang Q Tang J and Li Y: Mechanical stress influences the viability and morphology of human parametrial ligament fibroblasts. Mol Med Rep 15: 853-858, 2017.

40. Li BS, Guo WJ, Hong L, Liu YD, Liu C, Hong SS, Wu DB and Min J: Role of mechanical strain-activated PI3K/Akt signaling pathway in pelvic organ prolapse. Mol Med Rep 14: 243-253, 2016.

41. Hong S, Li H, Wu D, Li B, Liu C, Guo W, Min J, Hu M, Zhao Y and Yang Q: Oxidative damage to human parametrial ligament fibroblasts induced by mechanical stress. Mol Med Rep 12: 5342-5348, 2015.
42. Balint R, Cassidy NJ and Cartmell SH: Electrical stimulation: A novel tool for tissue engineering. Tissue Eng Part B Rev 19: 48-57, 2013.

43. Moon RT, Kohn AD, De Ferrari GV and Kaykas A: WNT and beta-catenin signalling: Diseases and therapies. Nat Rev Genet 5: 691-701, 2004.

44. Clevers H: Wnt/beta-catenin signaling in development and disease. Cell 127: 469-480, 2006.

45. Inestrosa NC and ToledoEM: The role of Wnt signaling in neuronal dysfunction in Alzheimer's Disease. Mol Neurodegener 3: 9, 2008.

46. Koehler A, Schlupf J, Schneider M, Kraft B, Winter C and Kashef J: Loss of Xenopus cadherin-11 leads to increased Wnt $/ \beta$-catenin signaling and up-regulation of target genes c-myc and cyclin D1 in neural crest. Dev Biol 383: 132-145, 2013.

47. Lei K, Nimnual A, Zong WX, Kennedy NJ, Flavell RA, Thompson CB, Bar-Sagi D and Davis RJ: The Bax subfamily of Bcl2-related proteins is essential for apoptotic signal transduction by c-Jun NH(2)-terminal kinase. Mol Cell Biol 22: 4929-4942, 2002.

48. Huang G, Hong L, Hu M, Zhou M, Chen Q and Lu D: Protective role of electrical stimulation in mechanical damage of rat dorsal root ganglion cells. J Chin Practical Diagnosis Ther 7: 646-649, 2019 (In Chinese).

This work is licensed under a Creative Commons Attribution-NonCommercial-NoDerivatives 4.0 International (CC BY-NC-ND 4.0) License. 